\title{
Bronchial asthma at high altitude: a clinical and laboratory study in Addis Ababa
}

\author{
BAYU TEKLU
}

From the Department of Internal Medicine, Addis Ababa University Medical Faculty, Addis Ababa, Ethiopia

ABSTRACT In a study designed to throw light on the natural history of asthma in Ethiopia, $91 \stackrel{\vec{x}}{\times}$ patients living at 2500 metres and attending asthma clinics in Addis Ababa underwent spirometric $\$$ and skinprick testing. Only eight had had symptoms of asthma before the age of 16. Sixty two had a ir history of allergic rhinitis and 16 had a family history of allergic rhinitis; 33 had a family history of ${ }^{\infty}$ asthma. In 30 cases asthma was worse from August to October. All patients had tried traditionalo remedies, usually without success; and all took modern drugs, oral combination bronchodilators being the most frequently used.

\section{Introduction}

Bronchial asthma is no longer rare in tropical and subtropical Africa, ${ }^{12}$ including Ethiopia. ${ }^{3-5}$ As relatively little is known about the natural history of asthma in Africa we have studied asthma in Ethiopians in Addis Ababa (altitude 2500 metres), looking at age of onset, family history, spirometric values, responses to skin tests for allergy, and traditional forms of treatment. Addis Ababa has a dry (October-May) and a rainy (June-September) season. The period of study was August to October as previous reports indicated an increase in cases of asthma during this period. ${ }^{24}$

\section{Methods}

Asthmatic patients seen at three clinics for adults in Addis Ababa were studied on the basis of a specially designed questionnaire. A clinical diagnosis of asthma was based on a convincing history of recurrent episodes of cough, wheezing, and shortness of breath. Because of the nature of the clinics, the sample was biased towards bank workers and hospital staff.

Skinprick tests were performed with Bencard solutions. The antigenic materials (selected on the basis of previous experience in Ethiopian patients) were cat fur, dog hair, horse hair, feathers, cotton flock, house

Address for reprint requests: Dr B Teklu, King Saud University (Abha branch), College of Medicine, Department of Internal Medicine, PO Box 641, Abha, Kingdom of Saudi Arabia.

Accepted 4 April 1989 dust, and house dust mite. Atopy was diagnosed by the presence of a weal of $3 \mathrm{~mm}$ or more diameter exclud-응 ing pseudopodia. Spirometry was carried out in 405 patients with a dry wedge spirometer (Vitalograph) before and after two puffs of isoprenaline.

\section{Results}

The age and sex distribution of 91 asthmatic patients and the age of onset of asthma are shown in table 1.0. There were three smokers, all male. Asthma had started before the age of 16 in eight patients only, ando in five it had developed after the age of 45. Asthma was perennial in two thirds of the patients (60) and worseo from August to October in one third (31). Two thirds? of the patients (62) had allergic rhinitis. There was a family history of allergic rhinitis in 16 cases and of asthma in 33 subjects.

In the $\mathbf{4 0}$ patients undergoing spirometry $\mathrm{FEV}_{1}$ was above $70 \%$ of the predicted value in $14,50-70 \%$ in $14 \%$ $30-50 \%$ in nine, and below $30 \%$ in three. After isoprenaline 16 patients showed no change or less than $5 \%$ increase in $\mathrm{FEV}_{1}$, seven showed a $5-15 \%$. improvement, and 17 an increase of more than $15 \% \mathrm{~N}$ Positive skin test responses were seen with cotton flock $(12 / 77)$ and most frequently with house dust mite (54) 77). Table 2 shows the precipitating factors considere to be important by the patients. Two women, includ ing a nurse, had avoided pregnancy so that theifo asthma would not be aggravated.

The two most popular traditional treatments fo asthma were the ingestion of raw beaten eggs and pure्e honey in the morning. Other treatment included the consumption of ostrich eggs, smoking dry excreta of 
Table 1 Age and sex distribution of 91 patients with asthma (numbers whose asthma started in each age range shown in parentheses)

\begin{tabular}{|c|c|c|c|c|c|c|c|}
\hline Age $(y):$ & $\leqslant 5$ & $6-15$ & $16-25$ & $26-35$ & $36-45$ & $46-55$ & $>55$ \\
\hline $\begin{array}{l}\text { Male } \\
\text { Female }\end{array}$ & $\begin{array}{l}0(1) \\
0(2)\end{array}$ & $\begin{array}{l}2(3) \\
1(2)\end{array}$ & $\begin{array}{l}2(11) \\
3(27)\end{array}$ & $\begin{array}{l}16(15) \\
32(13)\end{array}$ & $\begin{array}{r}12(9) \\
6(3)\end{array}$ & $\begin{array}{l}7(3) \\
5(2)\end{array}$ & $\begin{array}{l}3(0) \\
2(0)\end{array}$ \\
\hline Total & $0(3)$ & $3(5)$ & $5(38)$ & $48(28)$ & $18(12)$ & $12(5)$ & $5(0)$ \\
\hline
\end{tabular}

the elephant, and drinking ox bile. Two nurses drank their urine but experienced no improvement. Acupuncture and numerous unidentified herbal medications were tried by many but usually in vain. All patients took modern drugs simultaneously or on different occasions, 28 of the 91 taking more than one drug. Oral combination bronchodilators containing theophylline, ephedrine, and phenobarbitone (Franol, Tedral) were used most frequently (in 64 cases), though 23 patients used salbutamol inhalers and 30 were taking corticosteroids in the form of tablets (22), inhalers (2), or depot injection (6).

Table 2 Precipitating factors of asthma noted by patients

\begin{tabular}{lccc}
\hline & Yes & No & $\begin{array}{c}\text { Don't know } \\
\text { or uncertain }\end{array}$ \\
\hline Upper respiratory & & & \\
infection & 59 & 12 & 20 \\
Dust & 69 & 15 & 7 \\
Exercise & 45 & 18 & 28 \\
Cold weather & 51 & 8 & 32 \\
Weather changes & 35 & 10 & 46 \\
Diet & 8 & 12 & 71 \\
Aspirin & 5 & 32 & 54 \\
Psychological & 41 & 13 & 37 \\
$\quad$ factors & 35 & 3 & 53 \\
Odour & 17 & 19 & 55 \\
Alcohol & 34 & 11 & 46 \\
Flowers & 15 & 11 & 65 \\
Pets & 6 & 13 & 0 \\
Pregnancy & & & \\
\hline
\end{tabular}

\section{Discussion}

Although the study is biased in terms of the demography of the patients, this should have little effect on the reported age of onset of asthma. Asthma started before the age of 16 in only eight of the 91 patients, one of the lowest proportions reported from either Africa or Europe. ${ }^{16}$ Oglivie 7 reported that among 1000 asthmatic patients in the UK the morbidity and mortality from asthma was much worse in those whose asthma started after the age of 16 . Whether this is also true of the Ethiopians remains to be seen.

A past history of allergic rhinitis was obtained from $62(68 \%)$ of the patients and a family history of allergic rhinitis from $16(18 \%)$ and of asthma from $33(36 \%)$. The corresponding figures in Nigerian patients in Zaire were $27 \%$ and $25 \%$. ${ }^{\prime}$ A family history of asthma was reported by $50 \%$ of asthmatic subjects in Ghana ${ }^{8}$ and by $35 \%$ in England. ${ }^{6}$

All patients have tried some form of traditional medicine but usually in vain. Folklore medicine is so deeply rooted in the society that two patients from the medical profession drank their own urine. Many patients combined traditional forms of treatment with modern therapeutic agents. Unfortunately some of the more effective treatments, such as inhaled bronchodilators, are very expensive in Ethiopia.

\section{References}

1 Warrell DA, Fawcet IW, Harrison BDW, et al. Bronchial asthma in the Nigerian Savanna Region. A clinical and laboratory study of 106 patients with a review of the literature in the Tropics. $Q J$ Med 1975;44:325-47.

2 Lester FT. Bronchial asthma in Addis Ababa. Ethiopian Medical Journal 1977;15:95-9.

3 Tefferra A, Abdulkadir J. Analysis of medical admissions to the Princess Tsahai Memorial Hospital from April 1966 to March 1967. Ethiopian Medical Journal 1968;6:95-102.

4 Teklu B. Patterns of respiratory diseases in a general hospital in Addis Ababa. Ethiopian Medical Journal 1980;18:135-43.

5 Teklu B. Chronic disease prevalence in Ethiopian bank employees. Ethiopian Medical Journal 1982;20:49-54.

6 Hendrick DJ, Davies RJ, D'Souza MF, Pepys J. An analysis of skin prick test reactions in 656 asthmatic patients. Thorax 1975;30:2-8.

7 Oglivie AG. Asthma: a study in prognosis of 1000 patients. Thorax 1962;17:183-9.

8 Amin JT, Edoo BB. Bronchial asthma at the Korle Bu Teaching Hospital: a preliminary report. Ghana Medical Journal 1972;11:59-61. 